\title{
Review on the application of chemometrics for the standardization and authentication of Curcuma xanthorrhiza
}

\author{
1,2 Kusumadewi, A.P., ${ }^{1}$ Martien, R., ${ }^{1}$ Pramono, S., ${ }^{1,3}$ Setyawan, A.A. and ${ }^{1,4, *}$ Rohman, A. \\ ${ }^{1}$ Faculty of Pharmacy, Universitas Gadjah Mada, Yogyakarta 55281, Indonesia. \\ ${ }_{2}^{2}$ Medicinal Plant and Traditonal Medicine Research and Development Center, Tawangmangu, Central \\ Java. \\ ${ }^{3}$ Sekolah Tinggi Ilmu Kesehatan (STIKES) Muhammadiyah, Klaten, Central Java, Indonesia. \\ ${ }^{4}$ Centre of Excellence Institute for Halal Industry and Systems (PUI-PT IHIS), Universitas Gadjah Mada, \\ Yogyakarta 55281, Indonesia.
}

\begin{abstract}
Article history:
Received: 1 February 2021

Received in revised form: 28

March 2021

Accepted: 10 June 2021

Available Online: 31 January 2022
\end{abstract}

Keywords:

Temulawak,

Standardization,

Chemometrics,

FTIR spectroscopy

Chromatography

DOI:

https://doi.org/10.26656/fr.2017.6(2).044

\begin{abstract}
Temulawak (Curcuma xanthorrhiza Roxb.) or Javanese turmeric is one of Indonesia's native medicinal plants and is widely distributed throughout Southeast Asia. Temulawak contains some bioactive compounds having biological activities. The secondary metabolites in temulawak vary widely, depending on the environmental conditions where it grows. Temulawak as a raw material for herbal medicine is often faked with other rhizomes so that the analytical method capable of detecting the adulteration practice of temulawak is needed. The standardization of temulawak is a difficult task because the chemical compounds in temulawak are rather complex. In order to overcome the large and complex data, chemometrics is needed. The purpose of this paper was to highlight the application of chemometrics used during the standardization of temulawak through fingerprinting profile studies. During the literature searching, several databases namely Scopus, Web of Science, Pubmed and Google scholar were explored to get the relevant articles using specific keywords related to the topic. Some chemometrics techniques in combination with several instrumental techniques like spectroscopic and chromatographic methods are successfully used for the characterization and fingerprinting profiling of temulawak. Based on the data synthesized, chemometrics is powerful technique for treating the complex data intended for standardization of temulawak.
\end{abstract}

\section{Introduction}

In order to increase the preventive and promotive efforts in the health sector, herbal medicine is one of the people's choices to protect and maintain their health. Temulawak (Curcuma xanthorrhiza) is a native Indonesian medicinal plant widely spread to Southeast Asia (Nihayati et al., 2013). Temulawak, known as Javanese turmeric, is a rhizome widely applied as raw material for herbal and food ingredients. The demand for the herbal medicine industry is relatively high with an increase of $5.4 \%$ per year. The main chemical contents of C. xanthorhiza are xanthorrhizol accounting of 1.48$1.63 \%$, curcuminoids such as curcumin, demethoxycurcumin, bisdemethoxycurcumin accounting of $1-2 \%$, phelandren, camphor, tumerol, cineol, borneol, flavonoids, and sesquiterpenes (Husni, 2016). C. xanthorrhiza also contains some essential oils with chemical compounds of $\beta$-elemene, zingiberene, $\gamma$ - elemene, $\beta$-farnesene, $\alpha$-curcumene, benzofuran, $\alpha$ cedrene, epicurzerenone, ar-curcumene, germacrone, aromadendrene, $\alpha$ longipene, trans-caryophilene and curcuphenol (Rafi, Septaningsih and Heryanto, 2018). These compounds are responsible for the yellow to orange color, as well as for the biological activities of temulawak (Itokawa et al., 1985).

Currently, the awareness and public concern in the standardization, authenticity, and quality of herbal medicines has increased significantly, therefore, analytical methods have been developed to perform these tasks (Rohman, Rawar, Sudevi et al., 2020). Herbal medicines have many complex chemical contents characterized by specific markers to differentiate plant species. Their biological activities are the cumulative effects of many chemical compounds (Jia et al., 2017). Some factors contribute to the biological activities such as time harvesting, seasons, plant age, therefore, some 
efforts are needed to standardize the herbal raw materials in order to ensure the quality of the herbs (Gopi et al., 2019). Medicinal plants with complex chemical contents, of course, require a special method for quality controls through physico-chemical and molecular biology analyses (Ni et al., 2009). The process of identification and analysis of chemical constituents in medicinal plants can be performed by three approaches namely single component analysis through analysis of specific markers, fingerprinting analysis and metabolomic (Esteki et al., 2018) using some instrumental techniques including molecular spectroscopic and chromatography methods (Mazina et al., 2015). Temulawak is widely applied in herbal and traditional medicine products. Due to its high demand, temulawak is the potential to be substituted or adulterated with other species having a similar appearance such as Curcuma domestica (Muttaqin, 2018), therefore, it is very important to standardize temulawak to assure its quality (Windarsih et al., 2021).

The standardization of herbal medicine using fingerprinting profiling and metabolomics resulted in large numbers of responses which make it difficult to handle them. Fortunately, the special statistical package known as chemometrics could resolve this problem. Almost fingerprinting profiling and metabolomic studies used chemometrics for special purposes including pattern recognition and multivariate calibration (Granato et al., 2018). Chemometrics is a combination of mathematical and statistical techniques to process chemical data (Rohman., 2017). Some reviews on the application of chemometrics in herbal standardization include Traditional Chinese Medicines (Razmovski-Naumovski et al., 2010; Bansal et al., 2014; Li et al., 2020). Therefore, the purpose of this paper is to highlight the application of chemometrics used during the standardization of temulawak. In authentication of herbal medicine, the identification of the geographical origin of a medicinal plant including $C$. xanthorrhiza is part of drug analysis and part of quality control in pharmaceutical analysis. Identifying the geographic origin of plant material is a difficult task to do chemically, thus, an application of chemometrics is required to perform these tasks (Xie et al., 2006).

\section{Methods}

During performing this narrative review, we followed some steps as suggested in several papers reporting the writing of the review articles (Green et al., 2006; Gasparyan et al., 2011; Gregory and Dennis, 2018). The databases used during searching works of literature needed for writing review articles were Web of Science, Scopus, PubMed and Google Scholar. The keywords used for information search are Curcuma xanthorrhiza + chemometric OR Curcuma xanthorrhiza + standardization OR Curcuma xanthorrhiza + geographic origin.

\section{Chemometrics}

According to the International Chemometrics Society (ICS), the definition of chemometrics is described as "the science of relating chemical measurements made on a chemical system to the property of interest (such as concentration) through the application of mathematical or statistical methods (Rohman and Windarsih., 2020). Chemometrics is a branch of science, which relates the chemical analysis, mathematical or statistical methods (Gemperline., 2006). In chemometrics, some analytical purposes namely quantitative analysis using multivariate calibration, identification or classification using supervised or unsupervised pattern recognition are commonly applied in chemical sciences including authentication and standardization of herbal medicines (Brereton, 2003; Rohman et al., 2014). For example, in pattern recognition using chromatography methods, the samples are grouped according to their measurement (responses) using chromatogram which is the specific character of the analyzed sample (Beebe et al., 1998). The variables used during this task can be retention time, peak area, and peak height. The data were displayed in the form of a matrix consisting of rows and columns written numerically. Each row relates to one object and each column relates to certain features of the object or samples (Massart et al., 1997). Chemometric methods in data analysis are pervasive and important in the decisionmaking and problem-solving processes. The chemical analysis deals with complex mixtures, compounds, and their properties, which are often very complicated to be analyzed. Therefore, chemometrics is suitable for the analysis of herbal medicines which are typically complex in nature (Rohman, Rawar, Sudevi et al., 2020).

Today with the sophisticated development of statistical software and computers, chemometrics have become the main tool for processing data (Bansal et al., 2014). Several chemometric techniques applied in the standardization and authentication of herbal medicine are data preprocessing such as normalization and derivatization, data exploratory using Principal Component Analysis (PCA), unsupervised pattern recognition using Soft Independent Modeling of Class Analogy (SIMCA) and cluster analysis, supervised pattern recognition such as discriminant analysis and multivariate calibrations such as partial least square regression and principle component regression (Bansal et al., 2014).

In herbal standardization including C. xanthorrhiza, 
the chemometrics techniques are applied during fingerprint profiling and metabolomic studies (Bansal et al., 2014; Rohman, Ghazali, Windarsih et al., 2020). While in the authentication studies, chemometrics assisted in determining the origin of herbal medicine, adulteration of high-quality components of herbal medicines with the lower one, or identification of undeclared components in herbal products (Liu et al., 2020). Fingerprint profiling can be obtained from spectroscopic, chromatographic or electrophoretic data. The fingerprint profile must be able to display the similarities and differences in the analyzed samples (Cubero-Leon et al., 2014). The authentication of herbal medicine is a difficult task because many components of medicinal plants are unknown (Bauer, 1998). Fortunately, the chromatography and spectroscopy methods are able to show very strong authentication techniques through fingerprinting profiles. Combining the chemometrics with instrumental responses, the standardization of herbal medicine can be achieved with high precision and accuracy (Gad et al., 2013).

\section{Application of chemometrics in standardization of Curcuma xanthorrhiza}

Some chemometrics techniques of pattern recognition and multivariate calibrations combined with some instrumental techniques of spectroscopic and chromatographic methods were applied for the standardization of Temulawak. The variables used for chemometrics analysis using spectroscopic methods are absorbance values or ratios at specific wavelengths or wavenumbers, while variables exploited using chromatographic techniques were retention time, peak area, peak height or its ratios (Li et al., 2020). Table 1 compiled some chemometrics methods combined with instrumental techniques for the identification and discrimination of Temulawak, intended for standardization as described in Table 1 .

\subsection{Principal component analysis}

Principal component analysis (PCA) is an exploratory data analysis commonly used for the classification of samples (Irnawati et al., 2021), and two outputs in PCA commonly reported during classification or clustering are principal components (PCs) and loading plots. PCs are useful to identify any groupings in the data set. In addition, loading plots are shown from coefficients by which the original variables are multiplied in order to get PCs values. Loading plots describe the variables responsible for the separation and or classification of objects (Kim et al., 2010). The identification and discrimination of similar plants, such as turmeric ( $C$. longa), Javanese turmeric ( $C$. xanthorrhiza) and Bangle (Zingiber cassumunar), need to be done to ensure the quality of raw materials used (Rohaeti et al., 2015). Fourier transform Infrared (FTIR) spectroscopy combined with chemometrics can be the method of choice because of the analysis due to its nature as a fingerprint. Visual discrimination of the three species is indicated by the marker bands of FTIR spectra of each species. PCA followed by Canonic Variate Analysis (CVA) using FTIR spectra could classify these plants (Rohaeti et al., 2015).

PCA and discriminant analysis in combination with UV spectroscopy have been applied for the differentiation of four Curcuma species, namely Curcuma xanthorrhiza, C. longa, C. aeruginosa and $C$. mangga. These four rhizomes are widely used in herbal medicine and dietary supplements. The absorbance values of UV-Vis spectra at the wavelength of 210-500 $\mathrm{nm}$ were used as variables during differentiation. UV-Vis spectra were acquired in the interval of 200-800 $\mathrm{nm}$ and the standard normal variate was used for preprocessing the spectral data. Using two PCs (PC1 and PC2), PCA could differentiate Curcumas in which $\mathrm{PC} 1$ and $\mathrm{PC} 2$ were accounting for $79.30 \%$ and $12.0 \%$, respectively. In addition, DA using discriminant function 1 (DF1) and discriminant function 2 (DF2) could discriminate four species with an accuracy rate of the correctness of $95.5 \%$ (Rafi et al., 2018). PCA is also applied for the differentiation of C. xanthorrhiza, C. aeruginosa, and $C$. longa using two-dimensional NMR spectra. PC1 and PC2 were accounting for $63.1 \%$ and $28.1 \%$, respectively. Based on the identification of metabolites, curcumin and xanthorrhizol are responsible for this differentiation (Wahyuni et al., 2019).

Multivariate analysis of PCA using data set obtained from ${ }^{1} \mathrm{H}-\mathrm{NMR}$ spectra clearly discriminated pure and adulterated $C$. xanthorrhiza with $C$. aeruginosa as shown in Figure 1. PCA using two PCs showed a clear separation between pure $C$. xanthorrhiza, pure $C$. aeruginosa, and adulterated $C$. xanthorrhiza using several concentration levels of $C$. aeruginosa. Several original variables used for making the PCA model were reduced to be principal components, which explains the original variables. $\mathrm{PC} 1$ and $\mathrm{PC} 2$ described $73 \%$ of $\mathrm{PC} 1$ and $24 \%$ of $\mathrm{PC} 2$.

Research has been carried out on the existence of adulteration of $C$. xanthorrhiza with $C$. domestica, based on the fingerprint profiling by Thin Layer Chromatography (TLC). Fingerprinting profiles of $C$. xanthorrhiza were obtained from C. xanthorrhiza from Cianjur, Semarang, and East Nusa Tenggara, while the fingerprint profiles of $C$. domestica were obtained from Cianjur regions. Furthermore, the analysis was carried out by PCA. The results of PCA analysis showed that the 
Kusumadewi et al. / Food Research 6 (2) (2022) 1 - 8

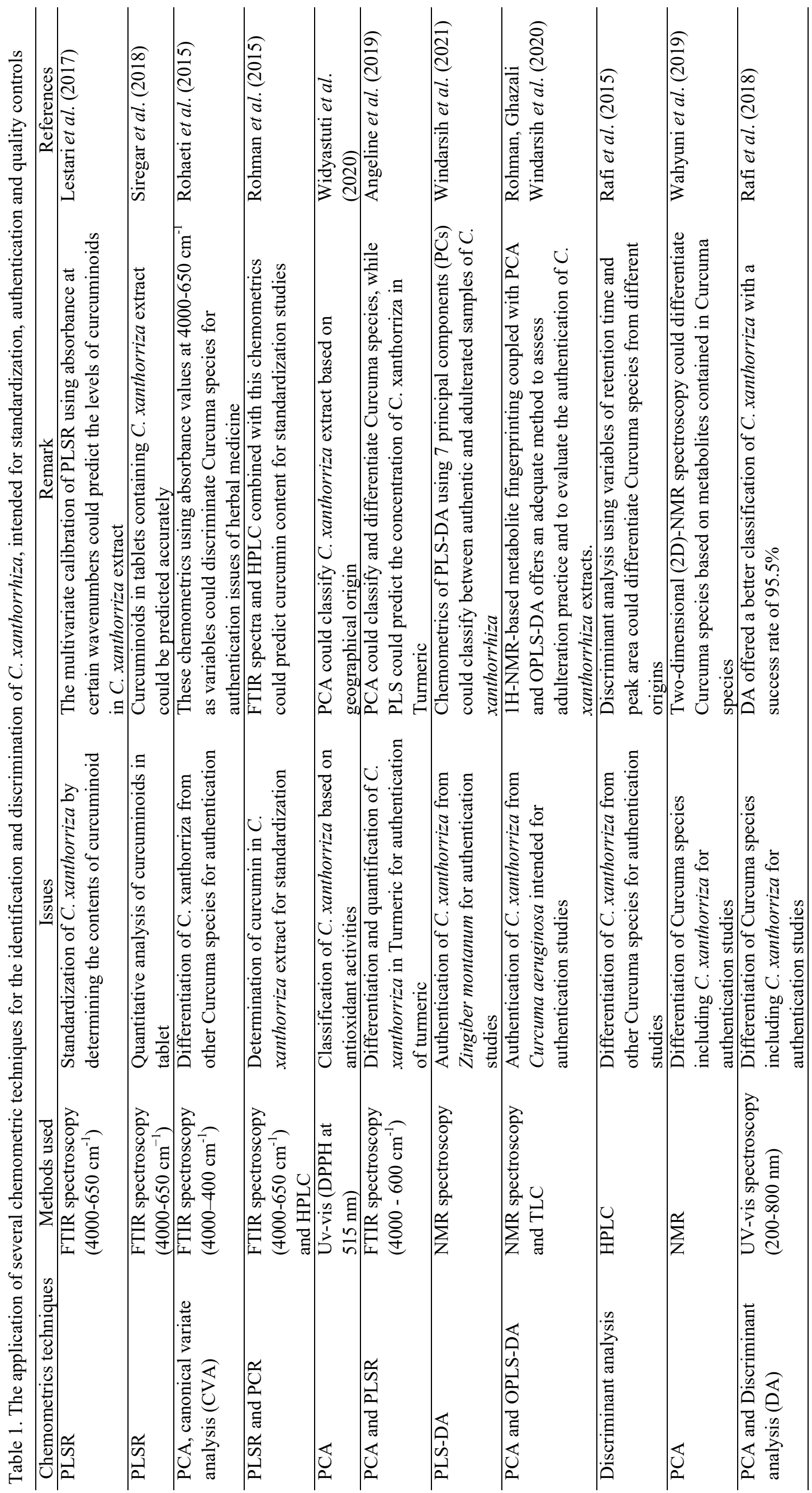


fingerprints of $C$. xanthorrhiza and $C$. domestica were in the different quadrants. However, analysis of instant curcuma samples showed that the samples were in the quadrant between $C$. xanthorrhiza and $C$. domestica (Muttaqin et al., 2018). PCA was also successfully used for the classification of other Curcuma species intended for hindering the adulteration practice (Windarsih et al., 2019).

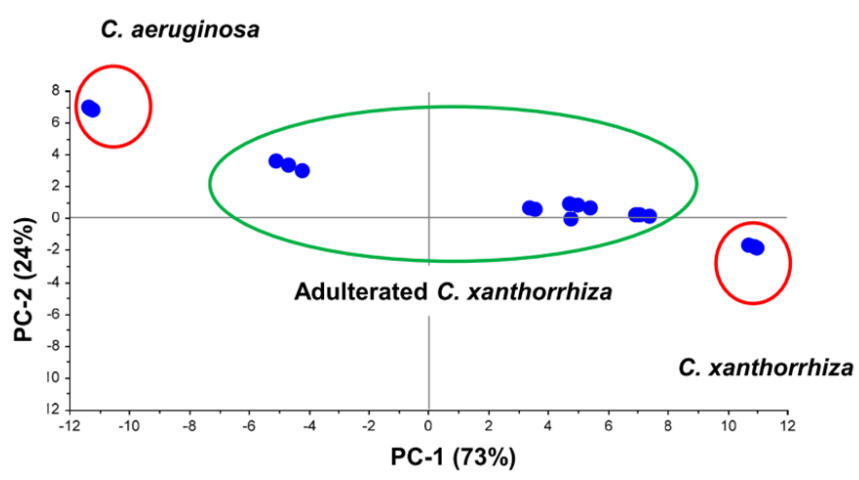

Figure 1. The score plots of principal component analysis for classification of pure C. xanthorrhiza, pure C. aeruginosa, and adulterated $C$. xanthorrhiza. The output was obtained using SIMCA 14.0 software (Sartorius, Malmo, Sweden). Source: Rohman, Wijayanti, Windarsih et al. (2020).

\subsection{Discriminant analysis}

Discriminant analysis (DA) is one of the supervised pattern recognitions commonly used for the discrimination or classification of objects/samples into several groups (Rohman and Putri, 2019). DA using algorithm of orthogonal projections to latent structures (OPLS) has been applied for the authentication of $C$. xanthorrhiza with $C$. aeruginosa using variables of ${ }^{1} \mathrm{H}$ NMR spectra. OPLS-DA was successfully applied for the classification of pure and adulterated $C$. xanthorrhiza with higher R2X (0.965), R2Y (0.958), and Q2(cum) (0.93) as shown in Figure 1 (Rohman, Wijayanti, Windarsih et al., 2020). Authentication and discrimination studies have also been conducted to differentiate the fingerprints of $C$. xanthorrhiza and $C$. longa based on curcuminoid levels using HPLC assisted with chemometrics of DA. This combination can separate C. xanthorrhiza and C. longa species (Rafi et al., 2015). In addition, the combination of $1 \mathrm{H}-\mathrm{NMR}$ and chemometric methods are promising for the authentication of medicinal plants (Windarsih et al., 2021). ${ }^{1} \mathrm{H}-\mathrm{NMR}$ spectroscopy and chemometrics have been applied to authenticate $C$. xanthorrhiza adulterated with Zingiber cassumunar. Partial least squarediscriminant analysis (PLS-DA) using 7 main components (PCs) was successfully classified the original sample and the adulterated C. xanthorrhiza with values of R2X (0.988), R2Y (0.998), and Q2 (0.993). The chemometrics of PCA and PLS-DA allows for the discrimination of pure $C$. xanthorrhiza and $C$. xanthorrhiza adulterated with Z. cassumunar (Wijayanti et al., 2019).

\subsection{Multivariate calibrations}

Multivariate calibration is one of the quantitative tools for prediction of analyte(s) of interest in herbal medicine like curcumin in Temulawak using several variables. Partial least square regression (PLSR) and principle component regression (PCR) are the most applied techniques (Keithley et al., 2009). PLSR using absorbance values of FTIR spectra at $4000-650 \mathrm{~cm}^{-1}$ has been used to predict the levels of curcumin (C), demetoxycurcumin (DM) and total curcuminoid (TC) in C. xanthorrhiza intended for the standardization. The actual contents of curcuminoid in the ethanolic extract of C. xanthorrhiza were previously determined using HPLC with a PDA detector. With PLSR, the $\mathrm{R}^{2}$ values of the calibration model for CUR, DMCUR and TCUR were $>$ 0.99. The levels of curcuminoid determined using FTIR spectroscopy-PLSR were not statistically significant compared with the HPLC method based on an independent sample t-test $(\mathrm{P}>0.05)$ (Lestari et al., 2017).

The combination of FTIR spectra-PLSR was also successfully applied for the prediction of the levels of curcumin in curcuma in C. longa and C. xanthorhiza. The actual levels of curcumin were determined using HPLC. PLSR using absorbance values at wavenumbers of $2000-950 \mathrm{~cm}^{-1}$ was suitable for the prediction of curcumin. The $\mathrm{R}^{2}$ values for the correlation between actual values and FTIR predicted values of curcumin were 0.96 and 0.99 with RMSEC values of 0.299 and 0.089 in C. longa and C. xanthorriza, respectively. High $\mathrm{R}^{2}$ values and low RMSEC values indicated high accuracy and precision of the analytical method (Rohman et al., 2015).

\section{Conclusion}

Several chemometrics techniques either pattern recognition (supervised such as discriminant analysis and unsupervised like principal component analysis) or multivariate calibrations like partial least square using variables generated from several instrumental techniques like spectroscopic and chromatographic methods are successfully used for characterization and fingerprinting profiling of herbal medicines including Temulawak intended for the authentication, quality control and standardization of herbal medicine. Based on the data synthesized, chemometrics is a powerful and meaningful technique for treating the complex data intended for the standardization and authentication of herbal medicines such as Javanese Turmeric. 


\section{References}

Angeline, E. Susidarti, R.A. and Rohman, A. (2019). Rapid authentication of turmeric powder adulterated with Curcuma zedoaria and Curcuma xanthorrhiza using FTIR-ATR spectroscopy and chemometrics. International Journal of Applied Pharmaceutics, 11 (5), 216-221. https://doi.org/10.22159/ ijap.2019v11i5.33701

Bansal, A., Chabra, V., Rawal, R.K. and Sharma, S. (2014). Chemometrics: A new scenario in herbal drug standardization. Journal of Pharmaceutical Analysis, 4(4), 223-233. https://doi.org/10.1016/ j.jpha.2013.12.001

Bauer, R. (1998). Quality criteria and phytopharmacy standardization: can acceptable drug standards be achieved. Drug Information Journal, 32(1), 101110. https://doi.org/10.1177/009286159803200114

Beebe, K.R., Pell, R.J. and Sheasholtz, M.B. (1998). Chemometrics: A Practical Guide. New York: Wiley.

Brereton, R.G. (2003). Chemometrics: Data Analysis for the Laboratory and Chemical Plant. New York: Wiley. https://doi.org/10.1002/0470863242

Cubero-Leon, E., Peñalver, R. and Maquet, A. (2014). Review on metabolomics for food authentication. Food Research International, 60, 95-107. https:// doi.org/10.1016/j.foodres.2013.11.041

Esteki, M., Simal-gandara, J., Shahsavari, Z., Zandbaaf, S. and Dashtaki, E. (2018). A review on the application of chromatographic methods coupled to chemometrics for food authentication. Food Control, 93, 165-182. https://doi.org/10.1016/ j.foodcont.2018.06.015

Gad, H.A. El-Ahmady, S.H., Abou-Shoer, M.I. and AlAzizi, M.M. (2013). The Application of Chemometrics in Authentication of Herbal Medicines: Review. Phytochemical Analysis, 24(1), 1-24. https://doi.org/10.1002/pca.2378

Gasparyan, A. Y., Ayvazyan, L., Blackmore, H. and Kitas, G.D. (2011). Writing a narrative biomedical review: Considerations for authors, peer reviewers, and editors. Rheumatology International, 31(11), 1409-1417. https://doi.org/10.1007/s00296-0111999-3

Gemperline, P. (2006). A Practical Guide to Chemometrics. London, UK: CRC Press. https:// doi.org/10.1201/9781420018301

Gopi, S., Amalraj, A., Jude, S. and Thomas, S. (2019). Bionanocomposite film based on potato, tapioca starch and chitosan reinforced with cellulose nanofibers isolated from turmeric residue. Journal of the Taiwan Institute of Chemical Engineers, 96, 644
-671. https://doi.org/10.1016/j.jtice.2019.01.003

Granato, D., Putnik, P., Kovadevic, D.B., Santos, J.S., Calado, V., Rocha, R.S., Da Cruz, A.G., Jarvis, B., Radionova, O.Y. and Pomerantsev, A. (2018). Trends in Chemometrics: Food Authentication, Microbiology, and Effects of Processing. Comprehensive Reviews in Food Science and Food Safety, 17(3), 663-677. https://doi.org/10.1111/1541 $-4337.12341$

Green, B.A., Johnson, C.D. and Adams, A. (2006). Writing Narrative Literature Reviews for Peerreviewed journals: Secrets of the Trade. Journal Chiropractice Medicine, 5(3), 107-117. https:// doi.org/10.1016/S0899-3467(07)60142-6

Gregory, A.T. and Denniss, A.R. (2018). An Introduction to Writing Narrative and Systematic Reviews - Tasks, Tips and Traps for Aspiring Authors. Heart Lung and Circulation, 27(7), 893898. https://doi.org/10.1016/j.hlc.2018.03.027

Husni, Z. (2016). Andrographis paniculata and Curcuma xanthorrhiza Extract and Active Constituents Inhibiting Morphine Glucuronidation. Malaysia: Universiti Sains Malaysia, Thesis.

Irnawati, I., Riswanto, D.F.O., Riyanto, S., Martono, S. and Rohman, A. (2021). The use of software package of $\mathrm{R}$ factoextra and FactoMineR and its application in Principal component analysis for authentication of oils. Indonesian Journal of Chemometrics Pharmaceutical Analysis, 1(1), 1-10, 2021. https://doi.org/10.22146/ijcpa.482

Itokawa, H., Hirayama, F., Fukanosi, K. and Takeya, K. (1985). Study of the antitumor bisabolene sesquiterpenoids isolated from Curcuma xanthorrhiza. Chemical and Pharmaceutical Bulletin, 33(8), 3488-3492. https://doi.org/10.1248/ cpb.33.3488

Jia, S., Du, Z., Song, C., Zhang, Y., Feng, Y. Xiong, C. and Jiang, H. (2017). Identification and characterization of curcuminoids in turmeric using ultra-high performance liquid chromatography quadrupole time of flight tandem mass spectrometry. Journal of Chromatography A, 1521, 110-122. https://doi.org/10.1016/j.chroma.2017.09.032

Keithley, R.B., Mark Wightman, R. and Helen, M.L. (2009). Multivariate concentration determination using principal component regression with residual analysis. TrAC - Trends in Analytical Chemistry, 28 (9), 1127-1136. https://doi.org/10.1016/ j.trac.2009.07.002

Kim, H.K., Choi, Y.H. and Verpoorte, R. (2010). NMRbased Metabolomic Analysis of Plants. Nature Protocol, 5(3), 536-549. https://doi.org/10.1038/ 
nprot.2009.237

Lestari, H.P., Martono, S. and Wulandari, R. (2017). Simultaneous Analysis of Curcumin and Demethoxycurcumin in Temulawak using FTIR spectroscopy and chemometrics. International Food Research Journal, 24(5), 2097-2101.

Li, Y., Shen, Y., Liang, Y.C. and Guo, D. (2020). Quality assessment of herbal medicines based on chemical fingerprints combined with chemometrics approach: A review. Journal of Pharmaceutical and Biomedical Analysis, 185, 113215. https:// doi.org/10.1016/j.jpba.2020.113215

Liu, F.J., Jiang, Y., Li, P., Liu, Y., Yao, Z., Xin, G. and Li, H. (2020). Untargeted metabolomics coupled with chemometric analysis reveals species-specific steroidal alkaloids for the authentication of medicinal Fritillariae Bulbus and relevant products. Journal of Chromatography A, 1612, 460630. https://doi.org/10.1016/j.chroma.2019.460630

Massart,

D.L.,

Vandeginste,

B.G.M., Buydens, L.M.C., De Jong, S., Lewi, P.J. and Smeyers-Verbeke J. (1997). Handbook of Chemometrics and Qualimetrics. Amsterdam, Netherlands: Elsevier.

Mazina, J., Vaher, M., Kuhtinskaja, M., Poryvkina, L. and Kaljurand, M. (2015). Fluorescence, electrophoretic and chromatographic fingerprints of herbal medicines and their comparative chemometric analysis. Talanta, 139, 233-246. https:// doi.org/10.1016/j.talanta.2015.02.050

Muttaqin, F.Z., Aida, N. and Asnawi, A. (2018). Detection of Adulterants in Raw Materials for Instant Temulawak (Curcuma xanthorrhiza ROXB) Using TLC Fingerprint Analysis. Pharmaceutical Journal of Indonesia, 15, 3059. https:// doi.org/10.30595/pharmacy.v15i1.3059

Ni, Y., Lai, Y., Brandes, S. and Kokot, S. (2009). Multiwavelength HPLC fingerprinting of complex substances: An exploratory chemometric study of a sample of Cassia seeds. Analitica Chimica Acta, 647 (2) $\quad 149-158 . \quad \mathrm{https} / / /$ doi.org/10.1016/ j.aca.2009.06.021

Nihayati, E., Wardiyati, T. and Retnowati, R. (2013). Curcumin content of temulawak rhizome (Curcuma xanthorriza Roxb.) was influenced by N. K and micronutrient B. Fe. Zn. Agrivita, 35(3), 218-226. https://doi.org/10.17503/Agrivita-2013-35-3-p218226

Rafi, A., Septaningsih, D.A. and Heryanto, R. (2018). Metabolite Profiling of Java Turmeric (Curcuma xanthorrhiza) Essential Oil with Different Harvest Times. Jurnal Kimia Sains dan Aplikasi, 21(4), 237-
241. https://doi.org/10.14710/jksa.21.4.237-241

Rafi, M., Jannah, R., Heryanto, R., Kautsar, A. and Septaningsih, D.A. (2018). UV-Vis spectroscopy and chemometrics as a tool for identification and discrimination of four Curcuma species. International Food Research Journal, 25(2), 643648.

Rafi, M., Wulansari, L., Heryanto, R., Darusman, L.K., Lim, L.W. and Takeuchi, T. (2015). Curcuminoid's Content and Fingerprint Analysis for Authentication and Discrimination of Curcuma xanthorrhiza from Curcuma longa by High-Performance Liquid Chromatography-Diode Array Detector. Food Analytical Methods, 8, 2185-2193. https:// doi.org/10.1007/s12161-015-0110-1

Razmovski-Naumovski, V., Tongkao-on, W., Kimbie, B., Qiao, V.L., Bailun, L., Li, K.M., Rougalis, B. Depo,Y., Meicun, Y. and Li, G.Q. (2010). Multiple Chromatographic and Chemometric Methods for Quality Standardisation of Chinese Herbal Medicines. World Science and Technology, 12(1), 99 -106. https://doi.org/10.1016/S1876-3553(11)600033

Rohaeti, E., Rafi, M., Syafitri, U.D. and Heryanto, R. (2015). Fourier transform infrared spectroscopy combined with chemometrics for discrimination of Curcuma longa, Curcuma xanthorrhiza and Zingiber cassumunar. Spectrochimica Acta Part A Molecular and Biomolecular Spectroscopy, 137, 1244-1249. https://doi.org/10.1016/j.saa.2014.08.139

Rohman, A. and Putri, A.R. (2019). The chemometrics techniques in combination with instrumental analytical methods applied in Halal authentication analysis. Indonesian Journal of Chemistry, 19(1), 262-272. https://doi.org/10.22146/ijc.28721

Rohman, A. and Windarsih, A. (2020). The application of molecular spectroscopy in combination with chemometrics for halal authentication analysis: A review. International Journal of Molecular Science, 21(14), 1-18. https://doi.org/10.3390/ijms21145155

Rohman, A., Rawar, E.A., Sudevi, S., Nurrulhidayah, A.F. and Windarsih, A. (2020). The use of chemometrics in combination with molecular spectroscopic and chromatographic methods for authentication of Curcuma species: A review. Food Research, 4(6), 850-1858. https://doi.org/10.26656/ fr.2017.4(6).345

Rohman, A., Ghazali, M.A., Windarsih, A., Irnawati, Riyanto, S., Mohd Yusof, F. and Mustafa, S. (2020). Comprehensive Review on Application of FTIR Spectroscopy Coupled with Chemometrics for Authentication Analysis of Fats and Oils in the Food Products. Molecules, 25(22), 1-28, 2020. https:// 
doi.org/10.3390/molecules25225485

Rohman, A., Wijayanti, T., Windarsih, A. and Riyanto, S. (2020). The Authentication of Java Turmeric (Curcuma xanthorrhiza) Using Thin Layer Chromatography and 1H-NMR Based-Metabolite Fingerprinting Coupled with Multivariate Analysis. Molecules, 25(17), 3928. https://doi.org/10.3390/ molecules 25225485

Rohman, A. (2017). The use of infrared spectroscopy in combination with chemometrics for quality control and authentication of edible fats and oils: A review. Applied Spectroscopy Reviews, 52(7), 589-604. https://doi.org/10.1080/05704928.2016.1266493

Rohman, A., Nugroho, A., Lukitaningsih, E. and Sudjadi. (2014). Application of vibrational spectroscopy in combination with chemometrics techniques for authentication of herbal medicine. Applied Spectroscopy Reviews, 49(8), 603-613. https://doi.org/10.1080/05704928.2014.882347

Rohman, A. Sudjadi, S., Devi, D., Ramadhani, D. and Nugroho, A. (2015). Analysis of Curcumin in Curcuma longa and Curcuma xanthorriza Using FTIR Spectroscopy and Chemometrics. Research Journal of Medicinal Plant, 9(4), 179-186. https:// doi.org/10.3923/rjmp.2015.179.186

Siregar, C., Martono, S. and Rohman, A. (2018). Application of Fourier transform infrared (FTIR) spectroscopy coupled with multivariate calibration for quantitative analysis of curcuminoid in tablet dosage form. Journal of Applied Pharmaceutical Science, 8(8), 123-130.

Wahyuni, D.S.C., Wardianti, M.P., Rinanto, Y. and. Marliyana, S.D. (2019). Metabolite Profiling of Three Curcuma Species (Zingiberaceae) Based on $\mathrm{H}$ -NMR Spectroscopy. Alchemy Jurnal Penelitian Kimia, 15(1), 79-85. https://doi.org/10.20961/ alchemy.15.1.23914.79-88

Widyastuti, I., Luthfah, H.Z., Hartono, Y.I., Islamadina, R., Can, A.T. and Rohman, A. (2020). Antioxidant Activity of Temulawak (Curcuma xanthorrhiza Roxb.) and its Classification with Chemometrics. Indonesian Journal of Chemometrics and Pharmaceutical Analysis, 1(1), 28-41. https:// doi.org/10.22146/ijcpa.507

Windarsih, A., Indrianingsih, A., Nisa, K. and Darsih, C. (2021). The use of ${ }^{1} \mathrm{H}-\mathrm{NMR}$ spectroscopy and chemometrics of pattern recognition for authentication of Curcuma xanthorrhiza adulterated with Zingiber montanum. IOP Conference Series: Material Science and Engineering, 1011, 012050. https://doi.org/10.1088/1757-899X/1011/1/012050

Windarsih, A., Rohman, A. and Swasono, R.T. (2019).
Application of ${ }^{1} \mathrm{H}-\mathrm{NMR}$ based metabolite fingerprinting and chemometrics for authentication of Curcuma longa adulterated with $C$. heyneana. Journal of Applied Research on Medicinal and Aromatic Plants, 13, 100203. https:// doi.org/10.1016/j.jarmap.2019.100203

Wijayanti, T., Riyanto, S., Lukitaningsih, E. and Rohman, A. (2019). Application of original article ${ }^{1} \mathrm{H}-\mathrm{NMR}$ spectra and multivariate analysis for the authentication of Curcuma xanthorrhiza from Zingiber cassumunar. International Journal of Applied Pharmaceutics, 11(4), 215-220. https:// doi.org/10.22159/ijap.2019v11i4.32417

Xie, H.P., Jiang, J., Chen, Z. and Shen, G. (2006). Chemometric Classification of Traditional Chinese Medicines Based on Their Geographical Origins Using the Near-Infrared Reflectance Spectrum. Analytical Science, 22(8), 1111-1116. https:// doi.org/10.2116/analsci.22.1111 